\title{
O debate francês acerca da instrução pública e seus desdobramentos no Brasil
}

ROGÉRIO GUIMARÃES MALHEIROS

Rede Municipal de Ensino de Parauapebas, Parauapebas, PA, Brasil

GENYLTON ODILON RÊGO DA ROCHA

Universidade Federal do Pará, Belém, PA, Brasil

RESUMO

Este artigo tem por objetivo analisar aspectos históricos das questões políticas, ideológicas e conceituais que estiveram presentes nas discussões referentes à instrução nacional francesa no final do século XVIII, enfatizando as proposições de Condorcet, no Rapport de 1792, como sendo base desse tipo de debate durante o processo revolucionário na França. Privilegiamos, portanto, analisar as prerrogativas discursivas dessa proposta e o certame suscitado a partir dela, pois resultaram, até mesmo, em novas proposições, entre elas as de Romme, Robespierre, Lepelletier e Lakanal. Trata-se de uma abordagem que nos proporciona a compreensão da base moderna do debate sobre instrução pública que se configurou no século XIX. Essa concorrência de ideias entre os franceses se estabeleceu como o grande legado teórico para os sistemas modernos de ensino, inclusive o brasileiro. Depreendemos, ainda, que a instrução defendida na França estava permeada pelos ideais de razão, moral e cientificismo.

PALAVRAS-CHAVE

instrução pública; história da educação; Rapport de Condorcet. 


\title{
THE FRENCH DEBATE ABOUT PUBLIC EDUCATION AND ITS DEVELOPMENT IN BRAZIL
}

\begin{abstract}
This article aims to analyze historical aspects of political, ideological and conceptual issues that were present in the discussions concerning French National Education in the late eighteenth century, emphasizing the proposals of Rapport of Condorcet in 1792, as the basis of this kind of debate during the revolutionary process in France. We focused, therefore, on analyzing the discursive privileges of these proposals and the events arising from it that resulted in even more new proposals, including those of Romme, Robespierre, Lepelletier and Lakanal. This is an approach that gives us the understanding of the modern basis of the debate on public education that was configured in the nineteenth century. This competition of ideas among French people was configured as the great theoretical legacy for modern education systems, including the Brazilian. We concluded also that the education defended in France was permeated by the ideals of reason, moral and scientism.
\end{abstract}

KEYWORDS

public instruction; history of education; Rapport of Condorcet.

\section{EL DEBATE FRANCÉS SOBRE LA EDUCACIÓN PÚBLICA Y SU DESARROLLO EN BRASIL}

RESUMEN

Este artículo tiene como objetivo analizar los aspectos históricos de las cuestiones políticas, ideológicas y conceptuales que se encontraban presentes en las discusiones relativas a la educación nacional de Francia a finales del siglo XVIII. Destacamos las propuestas de Condorcet en su Rapport (1792), como la base de este tipo de debate durante el proceso revolucionario en dicho país. Analicemos los privilegios discursivas de dicha propuesta y el evento levantado de ella, como resultado incluso en las nuevas propuestas, incluidas las de Romme, Robespierre, Lepelletier y Lakanal. Este es un enfoque que nos proporciona un punto de vista de base moderna con relación al debate sobre la educación pública que se configuró en el siglo XIX. Dicho intercambio de ideas entre los franceses se considera el gran legado teórico de los sistemas educativos modernos, como el brasileño. Concluimos, también, que la educación que se defendió en Francia fue permeada por los ideales de la razón, la moral y el cientificismo.

PALABRAS CLAVE

instrucción pública; historia de la educación; Rapport de Condorcet. 
Discutir as bases teóricas do que denominamos de sistema de instrução pública é também uma forma de depreendermos as premissas que fundamentaram as discussões travadas em vários momentos da história política do Império do Brasil, haja vista que, como bem pontuou Saviani (2009, p. 143), “[...] a questão da formação de professores exigiu uma resposta institucional apenas no século XIX, quando, após a Revolução Francesa, foi colocado o problema da instrução popular”. Por essa forma, optamos por revisitar as proposições de Marie Jean Antoine Nicolas de Caritat, Marquês de Condorcet, que, em seu Rapport de 1792, apresenta um projeto de organização da instrução nacional francesa, que, segundo autores como Arago (1968), Baker (1987), Coutel (1996), Granger (1989), Kintzler (1994), Silva (2010), entre outros, apesar de não ter sido concretizado na forma da lei, configurou-se como a base dos sistemas de instrução pública modernos, colocados em prática ao longo do século XIX em diversos países, de diferentes continentes, entre eles o Brasil.

Ainda sobre essa questão, Tanuri (2000, p. 62) evidencia que:

O estabelecimento das escolas destinadas ao preparo específico dos professores para o exercício de suas funções está ligado à institucionalização da instrução pública no mundo moderno, ou seja, à implementação das ideias liberais de secularização e extensão do ensino primário a todas as camadas da população.

Isso ratifica a necessidade de revisitarmos as teorizações sobre a instrução nacional francesa, pois foi a partir dessas discussões, iniciadas após a Revolução Francesa de 1789, que se multiplicaram, durante o século XIX, os fundamentos para os debates relativos à institucionalização de sistemas de instrução pública, além de fomentar discussões sobre a necessidade de se formar professores.

Como bem pontuou o historiador Hobsbawm (1996, p. 7):

Se a economia do mundo do século XIX foi construída principalmente sob a influência da revolução industrial britânica, sua política e ideologia foram constituídas fundamentalmente pela Revolução Francesa. A Grã-Bretanha forneceu o modelo para as ferrovias e fábricas, [...]; mas foi a França que fez suas revoluções e a elas deu suas ideias, a ponto de bandeiras tricolores de um tipo ou de outro terem-se tornado o emblema de praticamente todas as nações emergentes, e as políticas europeias (ou mesmo mundiais), entre 1789 e 1917, foram em grande parte lutas a favor e contra os princípios de 1789, ou os ainda mais incendiários princípios de 1793. A França forneceu o vocabulário e os temas da política liberal e radical-democrática para a maior parte do mundo. A França deu o primeiro grande exemplo, o conceito e o vocabulário do nacionalismo. A França forneceu os códigos legais, o modelo de organização técnica e científica e o sistema métrico de medidas para a maioria dos países. A Ideologia do mundo moderno atingiu, pela influência francesa, as antigas civilizações que até então resistiam às ideias europeias. Esta foi a obra da Revolução Francesa.

Podemos depreender, por essa forma, que os ideais franceses constituídos no período revolucionário, a exemplo das teorizações relacionadas à instrução nacional 
francesa, tornaram-se um conjunto de construções discursivas que permearam os debates tecidos ao longo do século XIX em relação à organização de sistemas de instrução pública e de formação de professores no mundo moderno.

\section{RAPPORT: O PROJETO PARA A ORGANIZAÇÃO DA INSTRUÇÃO NACIONAL FRANCESA}

Proporcionar a todos os individuos da raça humana os meios para satisfazer as suas necessidades, para garantir o seu bem-estar, conhecer e exercer os seus direitos, entender e cumprir suas obrigaçôes para garantir a modernização de sua indústria, para torná-lo capaz de funçôes sociais que ele tem direito a ser chamado, desenvolver toda a gama de talentos que recebeu da natureza e assim estabelecer uma igualdade entre os cidadãos e tornar a igualdade politica real e reconhecida por lei. Esse deve ser o primeiro objetivo de uma educação nacional e, por esse ponto de vista, é um dever do Estado a sua promoção.

Condorcet, 1792, tradução nossa

A epígrafe anterior, extraída do relatório e projeto de decreto denominado Rapport, apresentado à Assembleia Legislativa francesa em abril de 1792, é bem norteadora para o que pretendemos discutir neste artigo, isto é, para depreendermos as influências desses pensadores externos, principalmente franceses, para a discussão acerca da instrução pública, mais especificamente as questões relativas ao processo de institucionalização das escolas destinadas à formação de professores no Império do Brasil.

Como bem acentuamos anteriormente, Condorcet foi um dos filósofos que estiveram à frente das teorizações relacionadas ao que deveria representar o governo francês para seus cidadãos. Nesse sentido, no pós-revolução, teóricos como Mirabeau, Talleyrand, Robespierre, Danton, Romme, Lakanal e Lepelletier, além de Condorcet, passaram a teorizar sobre a institucionalização de uma "instrução nacional", ou seja, "ocupam-se dela e a defendem com entusiasmo não excedido mais tarde" (Luzuriaga, 1959, p. 41).

Filósofo, matemático, enciclopedista, membro da nobreza e influente político francês, Condorcet, desde 1791, dedicou-se às questões relacionadas à instrução pública, produzindo cinco ensaios intitulados "Memória da instrução pública", considerados como a base dos princípios constituintes dos sistemas de ensino modernos (cf. Arago, 1968; Baker, 1987; Coutel, 1996).

Quanto ao Rapport, conforme o trecho citado, Condorcet, em suas palavras iniciais, procura ressaltar que a oferta de uma instrução nacional, concebida como um dever do Estado, é também um mecanismo que propicia aos pretensos cidadãos franceses, do pós-revolução, os meios de prover e assegurar seu bem-estar, além de possibilitar-lhes conhecer e exercer seus direitos e deveres e capacitar-se para as funções sociais a que haveriam de serem chamados, isto é, seria também um importante mecanismo para proporcionar aos franceses uma igualdade de fato e dar 
realidade à igualdade política reconhecida pela lei, o que Condorcet, resumidamente, classificou como a primeira finalidade da instrução nacional.

Nessa perspectiva, fica claro o engajamento político de Condorcet para a institucionalização da instrução nacional, concebendo-a como um instrumento necessário e de total responsabilidade do Estado, que deveria provê-la a todos os cidadãos franceses. É interessante também que a ideia de "emancipação" do homem presente no Rapport, que também esteve no ideal revolucionário de 1789, potencializava o discurso pedagógico de universalização da escola, além de desvelar a necessidade de transformar os súditos do Antigo Regime em cidadãos franceses, transformação esta que só poderia ser concretizada por meio dessa institucionalização da chamada instrução nacional.

Condorcet, ainda no ano de 1791, quando dirigia o Journal D'Instruction Sociale, com um pensamento próprio de um enciclopedista, enfatizou que:

Nossas expectativas sobre a condição futura da humanidade podem ser resumidos em três pontos importantes: a destruição da desigualdade entre as nações, $o$ progresso da igualdade dentro de cada nação e, finalmente, a melhoria real dos direitos do homem.

[...]. O poder público não pode, nem mesmo sobre algum objeto, ter o direito de ensinar opiniões como verdades, e não deve impor a crença. (Journal D'Instruction Sociale, 1791, p. 1, tradução nossa)

Depreendemos, por essa forma, que seu pensamento estava intimamente ligado a um ideal de progresso da ciência e da razão, concebido como elemento fundamental para o desenvolvimento das potencialidades dos indivíduos. E postula suas críticas ao dogmatismo enfatizando que a sociedade não deve conceber o ensino de "opiniões como verdades" e nem aceitar a "imposição de crenças", isto é, razão e ciência estavam sistematicamente presentes em suas obras. ${ }^{1}$

Le Goff (2003, p. 246) esclarece que a ideia de progresso "desenvolve-se entre o nascimento da imprensa no século XV e a Revolução Francesa" de 1789. No entanto, percebemos que essa ideia de progresso ganha grande relevância entre os iluministas

1 As prerrogativas da ideia de progresso incorporaram-se aos discursos intelectuais do século XVIII “[...] e foi se convertendo em um credo que os constantes avanços tecnológicos ratificavam ao criar produtos e serviços que se transformavam em objeto de desejo e símbolos do progresso" (Dupas, 2006, p. 13). O progresso das sociedades humanas implicou ainda dimensões não redutíveis apenas ao progresso técnico-científico, de modo que foram também englobadas as questões morais. A Igreja católica, desse modo, era concorrente aos preceitos modernos de progresso e aos ideais presentes no Rapport de Condorcet, pois este acreditava que o progresso da ciência e da razão é que eram os elementos fundamentais para o desenvolvimento das potencialidades dos indivíduos, e não o dogmatismo religioso, enfatizando que a sociedade não deve conceber o ensino de "opiniões como verdades" nem aceitar a "imposição de crenças", o que denota que os ideais de instrução e formação dos cidadãos franceses de Condorcet concorreram com preceitos já disseminados pela religião durante o Antigo Regime, o que também pode ser exemplificado por meio do debate da laicidade. Acerca dessa questão, conferir: Arroyo (2005), Barbier (2005), Baubérot (2009), Elias (1993), Dupas (2006). 
e acentua-se nos séculos XIX e XX, ligada a uma concepção de desenvolvimento científico e tecnológico.

[...] a ideia de progresso se afirma antes de mais nada no domínio científico; que, depois de 1740, o conceito de progresso tende a generalizar-se e difundir-se nos domínios da história, da filosofia e da economia política. Ao longo de todo este período, com avanços e recuos, o que favorece o nascimento do progresso são, em primeiro lugar, as invenções, a começar pela imprensa, depois o nascimento da ciência moderna, tendo como episódios espetaculares o sistema Copérnico, a obra de Galileu, o cartesianismo e o sistema de Newton. É também o crescimento da confiança na razão e a ideia de que o mundo físico, moral e social é governado por leis. (idem, p. 247)

A Revolução Francesa de 1789, bem como seus filósofos, possuíam estreitos laços com essa ideia de progresso ligada ao desenvolvimento científico e à razão. No entanto, Le Goff (idem) pontua que se trata de uma ligação paradoxal, pois a revolução ocorrida na França desponta como um movimento que possibilitou o triunfo político e ideológico dessa noção de progresso. Mas, em contrapartida, nos documentos produzidos no decorrer do processo revolucionário, raramente se fez referência explícita a esse conceito. Assim, Le Goff (idem, p. 254) evidencia que não há formas explícitas desse conceito de progresso, mas há formas particulares dessa noção, "em especial às que figuram na divisa: liberdade, igualdade e fraternidade".

Outra antítese apontada por Le Goff (idem) refere-se ao fato de que a noção de progresso implica uma ideia de continuidade, enquanto a Revolução Francesa apresenta-se como uma ruptura, como um começo absoluto. Nesse contexto, Le Goff (idem) apresenta-nos uma particularidade do processo revolucionário francês. Todavia não afeta diretamente as teorizações posteriores, entre elas a de Condorcet, relativas à relação progresso humano e instrução nacional, haja vista que as citações apresentadas até o momento, referentes aos ensaios teóricos de Condorcet, todas estão permeadas pela ideia de progresso, entendido como desenvolvimento da ciência e da razão, como forma de promover aos cidadãos o desenvolvimento da sociedade e do próprio indivíduo.

Ainda no ano de 1791, Condorcet fora eleito deputado por Paris, passando a ser membro da Assembleia Legislativa francesa, onde ocupou a presidência do Comité D'Instruction Publique, passando a ser o relator do projeto de decreto que normatizaria a organização geral da instrução pública na França, apresentado à Assembleia Nacional francesa nos dias 20 e 21 de abril de 1792.

A apresentação foi feita em dois dias porque, no momento em que Condorcet estava apresentando o Rapport aos demais membros da Assembleia Nacional, este foi interrompido pela proposição de uma pauta urgente, isto é, o pedido de declaração de guerra contra os reis da Boêmia e da Hungria, ficando apenas para o dia 21 de abril o término da apresentação.

Cumpre destacar que, apesar de utilizarmos o Rapport de Condorcet para nossas análises e conclusões, este não foi tratado como consenso entre os membros da Assembleia Nacional francesa, pois havia sérias divergências em alguns pontos 
teóricos do projeto. Ante a essas divergências, até o final da legislatura de 1792, nenhuma medida fora tomada para que fosse colocado em prática o projeto de Condorcet, projeto este que influenciaria Romme, no dia 20 de outubro de 1793, a apresentar outro projeto de decreto acerca da instrução nacional francesa, no qual a considerava como estratégica para recriar a nação francesa, de maneira que pudesse inverter os códigos, inventar tradições e tecer o véu de uma identidade ainda por se fazer (cf. Boto, 1996).

Segundo Boto (idem, p. 156), as prerrogativas acerca da instrução pública tecidas por Romme concebiam que os progressos da razão tinham sempre o primado último para o norteamento do ensino ministrado, o que para Romme não se tratava apenas de ensinar, mas fundamentalmente de modelar corações e mentes com o intuito de fortalecer a permanência da revolução e precaver a possibilidade de um refluxo social e político, o que se afastava das premissas de Condorcet.

Robespierre, outro crítico da proposta de Condorcet, apresentou nova versão do projeto no dia 13 de julho de 1793, elaborada por Lepelletier, em que optaram por defender, diferentemente de Condorcet, que a instrução não é suficiente para regenerar a raça humana e que o Estado precisaria desenvolver mecanismos que possibilitassem a inculcação de uma moral entre os cidadãos. Essa contraproposta veio sob o ponto de vista dos jacobinos, pois, quando Condorcet expôs seu plano, os girondinos dominavam a Convenção, e, com o golpe de 2 de junho de 1793, os jacobinos tomaram o poder (idem).

Nesse contexto, os jacobinos passam a programar inúmeras medidas que caracterizariam o período conhecido como "Terror", como forma de eliminar os ditos "inimigos da revolução". Condorcet, na condição de girondino, fica sem qualquer possibilidade de poder defender sua versão do projeto.

Boto (idem, p. 168) demonstra as diferenciações entre o projeto de Condorcet e o de Lepelletier. A autora ressalta que aspectos como "o lugar social da escola instituída" é um dos pontos antagônicos entre os dois, uma vez que a proposta de Lepelletier visa a "fortalecer a estrutura coletiva da Revolução", enquanto a de Condorcet visava à formação do homem como ser ilustrado. Lepelletier propunha um homem consciente da missão revolucionária.

Essa autora aborda ainda outros aspectos de diferenciação entre as propostas de Condorcet e Lepelletier, como a intenção de aperfeiçoar o ser físico (corpo) e o ser moral (caráter), a conduta para com as crianças de ambos os sexos, os recursos educacionais, entre outros. Portanto, Boto (idem, p. 183) conclui que as especificidades da proposta de Lepelletier, isto é, o que a diferencia do Rapport de Condorcet, é que a educação é compreendida como "um instrumento revolucionário por excelência”.

Entrementes, reconhecemos no Rapport de Condorcet a base das discussões tecidas na França, após a revolução de 1789, acerca do processo de institucionalização da instrução nacional. Trata-se de um plano que marcará de forma indelével as aspirações burguesas de instrução pública de diversas regiões do planeta, entre elas o Império do Brasil, e nos permite perceber as premissas teóricas e discursivas que permearam a constituição de uma mentalidade moderna, com base na razão, na moral e no cientificismo. 
Nós pensamos que, neste plano geral de organização, nossa primeira preocupação deve ser tomada, por um lado, [com] a educação como sendo universal, por outro lado, deve ser também tão completa quanto às circunstâncias a permitam, que também deve dar toda a instrução que pode ser estendida a todos, mas se recusam a fazer qualquer parte do ensino superior público, como se fosse impossível o compartilhar com toda a massa de indivíduos; estabelecer um, porque é útil para quem o recebe, e o outro, porque é o mesmo para aqueles que não o recebem. A primeira condição de qualquer instrução é para ensinar as verdades únicas, as instituições que [pelas quais] o público passa devem ser tão independentes, quanto possível, de qualquer autoridade política, e como, no entanto, a independência não é absoluta, segue o mesmo princípio, não deve torná-los dependentes que da Assembleia de Representantes do Povo, porque, de todos os poderes, é o menos corruptível, mais distante de ser conduzido por interesses particulares, os mais [poderes do Estado] sob a influência da opinião geral de homens esclarecidos e, especialmente, porque sendo que dos quais emanam, essencialmente, todas as alterações, portanto, é [o interesse particular] o inimigo do progresso sob as luzes, menos oposição para as melhorias que esse progresso deve levar. (Condorcet, 1792, tradução nossa)

Para além das questões relativas ao entendimento sobre a ideia de progresso e desenvolvimento das potencialidades humanas, no eixo introdutório do Rapport, Condorcet ressalta a questão da universalização da educação. Ou seja, conforme a citação anterior, Condorcet enfatiza a necessidade de uma educação de caráter universal, que seja ofertada a todos os cidadãos franceses, o que para a maioria seria uma primeira oportunidade de acesso à instrução.

O filósofo ressalta ainda a necessidade de autonomia para as instituições destinadas à instrução, no caso de uma não autonomia plena, especificamente na França. Tal autonomia deveria estar ligada à Assembleia de Representantes do Povo, pois seria a menos corruptível, tendo em vista que Condorcet defende a não interferência de qualquer autoridade política na produção de novas "verdades" nem no ensino de teorias contrárias à sua política e interesses particulares. Condorcet afirma que o dever primordial da instrução é o de ensinar aos indivíduos as "verdades" únicas, o que denota o cientificismo de suas proposições teóricas.

Nota-se também a presença de argumentos que denotam, conceitualmente, a ideia de progresso, enfatizando o desejo comum dos cidadãos franceses em desenvolver suas faculdades naturais ao ser humano e em aperfeiçoar a sociedade como um todo, enfatizando a premissa de que a instrução necessita acompanhar o indivíduo para além da instituição escolar, como meio de estabelecer parâmetros concretos para o desenvolvimento da vida individual e coletiva do cidadão francês.

Nós distinguimos cinco níveis de instrução, sob o nome: $1^{\circ}$ escolas primárias, $2^{\circ}$ escolas secundárias, $3^{\circ}$ institutos, $4^{\circ}$ liceus, $5^{\circ}$ de Sociedade Nacional de Ciências e Artes. 
É ensinado nas escolas primárias o que é necessário para cada indivíduo viver em sociedade e desfrutar de todos os seus direitos. (idem, tradução nossa)

O projeto de decreto elaborado pelo Comité D'Instruction Publique, presidido pelo então deputado Marquês de Condorcet, distinguiu cinco níveis para a instrução a ser colocada em prática na França, isto é, as escolas primárias, ${ }^{2}$ com o objetivo de desenvolver uma instrução cívica e prática, ou seja, a instrução necessária para cada indivíduo conhecer os mecanismos para a plena convivência social e desfrutar de seus direitos; as escolas secundárias, ${ }^{3}$ que passariam a ensinar, especificamente, matemática e ciências, além de promover os conhecimentos necessários aos futuros professores do primeiro nível de ensino; os institutos, ${ }^{4}$ instituições que teriam como

2 Nesse primeiro nível de ensino, percebemos a relevância dada pelos teóricos franceses para a disseminação da educação primária. Considerando que as escolas primárias proporcionariam aos franceses as devidas possibilidades de aprenderem a ler e escrever, as regras gramaticais básicas, aritmética, métodos simples para medir com precisão a terra, conhecer as descrições básicas das produções do país, os métodos de agricultura e as artes, o desenvolvimento de ideias iniciais e regras morais de conduta para a vida em sociedade, bem como os princípios de ordem social que pudessem ser apresentados às crianças francesas.

3 Quanto às escolas secundárias, o Rapport demonstra, por meio dos argumentos de seu redator, Marquês de Condorcet, que se trata de instituições escolares destinadas a crianças cujos pais necessitam permanecer por mais tempo no trabalho. É interessante perceber que, para além das questões relativas à instrução, as escolas secundárias possuíam também a finalidade de garantir a permanência por mais tempo dos pais no ambiente de trabalho, uma lógica eminentemente capitalista, isto é, quanto mais tempo os pais pudessem trabalhar, despreocupados com seus filhos, maior seria o lucro do empregador e, por conseguinte, a própria arrecadação do Estado francês aumentaria. Nesse contexto, a criação das escolas secundárias possuía claros objetivos políticos, econômicos e sociais. É interessante notar que as escolas secundárias seriam instaladas apenas em distritos e cidades com mais de quatro mil habitantes, o que significa que estas possuíam a missão de atender apenas a selecionados núcleos urbanos, deixando as demais localidades, com população inferior ao número de habitantes estipulado, fora do eixo a ser atendido, demonstrando claramente que o interesse econômico estava em primeiro plano, em um projeto de decreto que a todo momento se justifica por meio do princípio da igualdade, considerando que no próprio Rapport há a nítida afirmação de que não haverá desigualdade na distribuição dessas instituições, o que consideramos, no mínimo, uma contradição. Há ainda o princípio de normatização de um currículo comum a todas as instituições desse nível de ensino, pois afirma que o "ensinamento será o mesmo em todos", ministrados por um, dois ou três professores, o que seria definido pelo número de alunos matriculados na instituição.

4 Condorcet ressalta que os institutos englobariam elementos de todas as áreas do conhecimento humano, o que estaria estritamente de acordo com o objetivo desse nível de instrução, ou seja, o de habilitar seus alunos para cumprir as funções públicas a que seriam chamados. Como já havíamos mencionado, trata-se também de uma instituição destinada à formação de professores, que passariam a atuar no nível anterior, isto é, nas escolas secundárias, o que representaria também um mecanismo eficiente para o aperfeiçoamento destes, pois, em geral, já atuavam como professores da escola primária. Enquanto os institutos representariam também, com maior ênfase, uma instituição de formação de professores, além de uma instituição de aperfeiçoamento. Quanto ao currículo do terceiro nível de instrução na França, segundo proposição de Condorcet, este contemplaria não apenas 
objetivo principal a formação de professores para as escolas primárias e secundárias; os liceus, ${ }^{5}$ que promoveriam o treinamento, isto é, aperfeiçoamento de professores, o que poderíamos denominar de formação continuada; e, por último, a sociedade nacional das ciências e das artes, ${ }^{6}$ cuja missão seria a de liderança escolar, enriquecendo o patrimônio cultural e da divulgação dos resultados.

O Rapport estabelece ainda a proposição de que nesses quatro primeiros níveis de ensino, isto é, nas escolas primárias, nas escolas secundárias, nos institutos e nos liceus, a instrução ofertada seria totalmente gratuita, considerada como um salutar mecanismo para garantir à nação a formação de cidadãos trabalhadores aptos ao serviço, cientistas capazes de contribuir significativamente para o progresso da nação, bem como o de formar e capacitar professores para o serviço de instruir os cidadãos, além de ser encarada como um eficiente mecanismo para amenizar as diferenças econômicas entre as classes que compõem a sociedade francesa.

Outra questão interessante de se abordar acerca das proposições de Condorcet está relacionada aos denominados "livros elementares". Segundo a proposição do filósofo, os livros referentes aos três primeiros níveis de instrução deveriam abordar estudos específicos de cada ciência, bem como de suas subdivisões, o que perpassaria por um processo de seleção do que deveria ser ensinado em cada nível de ensino.

Os conteúdos científicos a serem trabalhados a partir do quarto nível passariam por um processo de seleção realizada pelo próprio professor, o que denota certa autonomia metodológica aos professores que atuariam nos liceus franceses, fato este que Condorcet afirma ser um mecanismo para conter os efeitos da violação dos "livros elementares" que viessem a ser corrompidos por doutrinas nocivas aos princípios até aqui defendidos por ele, principalmente o da liberdade.

o que é útil saber como homem, cidadão, como trabalhador de qualquer profissão, mas também tudo o que pode ser fornecido para cada divisão principal dessas profissões.

5 Os liceus, enquanto quarto nível de instrução a ser colocada em prática na França, é concebido como uma instituição destinada à formação de cientistas, ao aperfeiçoamento de professores e para a instrução de indivíduos que desejam seguir carreira profissional que requisite o aprendizado de uma ou mais ciências. Condorcet afirma que é por meio dessas instituições, os liceus, que os conhecimentos, o que ele mesmo denominou de "verdades", serão selecionados e transmitidos para as futuras gerações.

6 A sociedade nacional das ciências e das artes, considerada como o último nível da instrução nacional francesa, é uma sociedade nacional criada para supervisionar e dirigir instituições de ensino, para proporcionar o desenvolvimento da ciência e da arte, bem como reconhecer, promover, colocar em prática e disseminar descobertas científicas úteis à sociedade. Nesse nível de ensino, já não é a instrução especial das crianças, ou mesmo dos homens, que é a especialidade, mas a investigação de toda uma geração. Ou seja, está intimamente ligada a um ideal de promover aperfeiçoamentos à razão humana. $\mathrm{O}$ mesmo não se detém ao ensino das luzes ao indivíduo particular, mas à sociedade como um todo, de forma que possibilite, segundo as proposições de Condorcet, a compreensão de que o conhecimento precisa ser enriquecido por novas verdades, como forma de aperfeiçoar a mente humana para o desenvolvimento de novas maneiras de acelerar e promover $o$ progresso científico e social. Ou seja, essa instituição possuía a missão ímpar de publicizar e aperfeiçoar as descobertas e os inventos científicos. 
O quarto nível de instrução pública francesa, portanto, seria o meio pelo qual poderiam ser contidos os efeitos da corrupção, resguardando o ensino das "verdades únicas", como pontuou Condorcet.

[...] Nas aldeias onde haverá apenas uma escola primária, as crianças de ambos os sexos serão admitidas e receberão a mesma instrução de um mesmo professor.

Quando uma aldeia ou cidade tiver duas escolas primárias, uma delas será atribuída a um professor, e as crianças serão separadas por sexos. Essa é a única disposição relativa à educação das mulheres, que faz parte do nosso trabalho; em primeiro lugar essa instrução será objeto de uma relação especial, e, de fato, se observarmos que, em poucas famílias menos abastadas, a educação das crianças é quase inteiramente de responsabilidade de suas mães [...]. (idem, tradução nossa)

Torna-se relevante percebermos que a discussão tecida por Condorcet acerca da instrução de crianças do sexo feminino é bastante breve e simplificada. O Rapport ressalta que, no caso de haver uma escola primária, as crianças de ambos os sexos teriam de compartilhar o mesmo ambiente e o mesmo professor. E, no caso de existirem duas unidades de escola primária, as crianças seriam separadas, tendo como paramêtro para separação o sexo de cada uma, ou seja, uma escola ficaria encarregada da instrução de crianças do sexo masculino, enquanto a outra, das do sexo feminino, e cada uma das instituições com apenas um professor.

A proposição de organização da instrução nacional francesa, nesse sentido, reconhece que há diversas situações sociais em que a obrigação de acompanhar o processo de instrução das crianças acaba ficando a cargo das mães, levando-os a observar os casos em que não poderia haver mais de uma escola primária, além de reconhecer a necessidade da instrução de mulheres.

Depreendemos ainda que as proposições presentes no Rapport partem de um ideal filosófico livre de qualquer interferência política, no sentido dos interesses particulares, de qualquer velho hábito, ou seja, livre de qualquer pensamento que esteve presente anteriormente ao processo revolucionário, durante o Antigo Regime.

Condorcet afirma ainda que foi baseado principalmente nesses pressupostos filosóficos que procurou estabelecer os parâmetros de seleção e classificação dos objetos e objetivos da instrução nacional francesa, que acabam por privilegiar a premissa de que as ciências consideradas essenciais ao desenvolvimento das potencialidades do ser humano, da moral, da razão, do princípio de justiça, seriam elementos fundamentais para a formação comum do cidadão francês.

Os princípios da moralidade ensinados nas escolas e institutos serão aqueles que, baseados em nossos sentimentos naturais e na razão, também pertencem a todos os homens. A Constituição, reconhecendo o direito de todo indivíduo de escolher sua religião, ao estabelecer a plena igualdade entre todos os habitantes da França, não permite admitir, na educação pública, um ensino que, ao repelir os filhos de alguns cidadãos, destruiria a igualdade de benefícios, o que daria 
uma vantagem a particulares dogmas, contrariando a liberdade de opinião. Por isso, era estritamente necessário separar os princípios morais de qualquer religião em particular, e não admitir o ensino na educação pública de qualquer culto religioso. Cada um deve ser ensinado nos templos por seus próprios ministros. (idem, tradução nossa)

Outro princípio difundido pelos teóricos franceses e ratificado por Condorcet em seu projeto de lei, o Rapport, está relacionado à não interferência de qualquer credo religioso no processo de instrução nacional, o que esteve substanciado pela premissa de que cada indivíduo possui a faculdade de escolher sua própria doutrina religiosa, estando totalmente de acordo com o princípio de liberdade defendido pelos revolucionários burgueses.

Desse modo, a instrução nacional defendida por Condorcet jamais poderia admitir qualquer interferência religiosa em seu percurso. Pelo contrário, Condorcet afirmava que era extremamente necessário separar os princípios morais de qualquer religião em particular, propondo o ensino e a divulgação de seus dogmas ao ambiente restrito de seus templos, o que seria de responsabilidade dos ministros de cada culto.

Destarte, os princípios da moralidade ensinados nas escolas e nos institutos serão aqueles que, baseados nos sentimentos naturais do ser humano e na própria razão, e em conformidade com o princípio da laicidade, conjugam e norteiam as reflexões de uma instrução comum a todos os homens.

O plano que apresentamos à Assembleia foi combinado depois de analisar o estado atual do Iluminismo na França e na Europa, tanto quanto as observações tecidas por vários séculos poderiam nos ensinar sobre o progresso da mente humana em ciência e nas artes, e, finalmente, depois que nós pudermos esperar e prever a sua evolução posterior. (idem, tradução nossa)

Ao finalizar as propostas presentes no Rapport, Condorcet ressalta que as proposições tecidas no projeto de lei que normatizaria a instrução nacional francesa estavam totalmente pautadas nas análises e estudos feitos acerca do estado do pensamento Iluminista na França e em todo o continente europeu, observando criteriosamente a historicidade do pensamento humano, de forma que pudesse desvelar o progresso da mente humana, por meio da ciência e da arte, com claros objetivos de analisá-lo para que pudesse estabelecer os parâmetros necessários a suas proposições para a institucionalização da instrução nacional na França.

É bem verdade que vários discursos relacionados à instrução pública foram pronunciados e escritos em diversos momentos do processo revolucionário francês - na Constituinte, na Assembleia Legislativa, na convenção e na própria redação da Declaração dos Direitos do Homem e do Cidadão, de 23 de junho de 1793. No entanto, consideramos relevante nos deter, conforme nossa proposição inicial, principalmente nos pressupostos discursivos acerca da institucionalização da instrução nacional presentes no Rapport de Condorcet, pois este apresenta os parâmetros científicos que estavam em voga na Europa no final do século XVIII e início do XIX. 
Não queremos aqui afirmar que as proposições francesas foram as primeiras iniciativas para a institucionalização da instrução pública no Ocidente, pelo contrário, pois discursos semelhantes já haviam sido proferidos em momentos anteriores à revolução na França, a exemplo das iniciativas da Reforma e da Contrarreforma. Porém, "[...] foi somente durante a Revolução Francesa que se concretizaria, pela primeira vez, a ideia de uma instituição pública e laica [...]" de ensino (Villela, 1990, p. 22).

As proposições tecidas por Condorcet, após o processo revolucionário, estiveram eminentemente permeadas de ideais iluministas e cientificistas. Os princípios de liberdade e de igualdade foram acessados a todo momento, uma vez que Condorcet evidenciava, em diversos trechos de sua redação, a liberdade de pensamento e a universalização de oportunidades para a formação dos cidadãos franceses.

Torna-se relevante também percebermos que, para Condorcet, o universalismo, para além do princípio de igualdade, é também um preceito antagônico ao relativismo, caracterizando a escola como um lugar de rupturas, e não de complementaridade entre ambos. $\mathrm{O}$ relativismo, dessa maneira, não poderia estar presente na instrução dos indivíduos, pois, caso isso acontecesse, estar-se-ia impondo a todos o que é específico de alguns. Enquanto o preceito de universalização estaria intimamente ligado ao epistêmico, como sinônimo de verdade e em oposição ao erro, à supertição e ao preconceito.

O universal seria relativo ao espírito humano, ao genérico, e não ao indivíduo e a grupos específicos. Para Condorcet, a instrução deveria sobrepor à singularidade e propiciar aos indivíduos os mecanismos necessários para alcançar o ideal de universalização da instrução. No entanto, Condorcet ressalta que a instrução dos cidadãos, "[...] antes de ser um edifício com base firme em elementos universais irrevogáveis, apresenta-se mais como um quadro móvel, cujos elementos são instáveis e sujeitos a ajustes constantes" (Silva, 2010, p. 2).

O primeiro objetivo da educação pública, como o mais fundamental,é fazer com que as pessoas realmente tenham direitos iguais e se tornem verdadeiramente livres para escolher e agir por si mesmas, através da preparação de cada cidadão para desempenhar funções comuns da vida cotidiana. (Baker, 1987, p. 386, tradução nossa)

Baker (idem) ratifica o que representou as proposições de Condorcet para a normatização da instrução nacional francesa, enfatizando que a institucionalização dessa instrução pública passou a ser considerada como condição para a plena liberdade do cidadão.

Autores como Kintzler (1994), Coutel (1996) e Silva (2010) ressaltam que Condorcet fez, em suas teorizações, uma nítida distinção entre instrução e educação, sendo a primeira a condição de liberdade do homem, baseada na ciência e na razão, e de total responsabilidade do poder público, enquanto a segunda estaria eminentemente envolvida nos campos da moral, do político e do religioso, sendo totalmente ligada aos ambientes privados. 
Para Condorcet, a educação ocorre na privacidade das famílias, comunidades, igrejas etc., e, quando a pretensão de educar assume o dever de instruir, a escola tende a ser um substituto para as famílias, comunidades e instituições privadas. Essa relação assimétrica de jurisdições entre escola pública e espaço privado pressupõe uma relativa autonomia em relação à outra e é, assim, um obstáculo à hegemonia de um sobre o outro, ou ao domínio da política ou da religião sobre a sociedade.

Não podemos deixar de rever as questões relativas à instrução de mulheres teorizadas por Condorcet. Mais uma vez baseado no princípio de igualdade, o filósofo ressalta a importância de se promover aos cidadãos do sexo feminino iguais condições de acesso à instrução, tendo em conta que muitas mulheres tornavam-se viúvas, sendo obrigadas a assumir a responsabilidade pela família, além de, como já havíamos pontuado anteriormente, serem as responsáveis pela educação das crianças no ambiente doméstico, entre outras questões que fundamentaram as proposições de Condorcet sobre a instrução feminina. Nesse sentido, a não promoção das mulheres ao acesso à educação semelhante à dos homens estaria ferindo o princípio de caráter essencial para Condorcet, o da igualdade.

Acerca dessa questão, Boto (2003, p. 747) enfatiza:

[...] tratava-se de uma dedução lógica do princípio da natureza - que quis todos iguais e que distribuiu com seus próprios critérios (naturais) os talentos, independentemente de fortunas, independentemente de privilégios de castas e independentemente do gênero. Condorcet defendia as mulheres, talvez, por razões lógicas.

Em síntese, como bem pontuou Boto (idem), tratava-se de uma observância aos direitos universais do homem e uma tentativa de eliminar as desigualdades de acesso à educação entre os sexos, haja vista que concebia a mulher como qualquer outro ser humano, tendo as mesmas qualidades e, por conseguinte, os mesmos direitos. Condorcet afirma ainda que os indivíduos, consciente ou inconscientemente, que votam contra o direito de outra pessoa, qualquer que seja sua religião, cor da pele ou sexo, acabam por renunciar aos seus próprios direitos também (cf. Silva, 2010).

Autonomia aos professores e à instituição escolar é outro ponto abordado por Condorcet no Rapport. Nele Condorcet afirma que a escola pública precisa ser reconhecida como elemento fundamental para a liberdade do homem, por isso deve ser protegida por lei de qualquer interferência política, econômica ou mesmo dos pais de alunos. O que se aplica também aos professores, pois Condorcet enfatiza que eles deveriam estar isentos do monopólio de qualquer partido político ou corporação profissional, e ainda de qualquer pressão civil ou política (cf. Coutel, 1996).

Condorcet, conscistentemente influenciado pelo velho ideal cartesiano de uma "moral", concebe essa "ciência moral" como a base do conhecimento racional necessário à formação do cidadão francês. Não se trata, obviamente, de uma moral transcendental defendida pela religião, mas de uma moral científica e fundamentada na razão (cf. Granger, 1989). 
A formação da razão e da moral do povo, por meio da instrução pública, nesse contexto, exigiria uma recusa, por parte do poder público, dos princípios particulares das religiões, de maneira que não admitisse que os ensinamentos das doutrinas religiosas se tornassem oficiais. No entanto, cada indivíduo teria resguardado, pelo poder público, seu direito de frequentar uma igreja, ou seja, a liberdade de culto e o ensino laico foram também objetos de análise e teorização de Condorcet, o que para ele se tratava de um "direito de consciência".

Quanto ao livro didático, ou melhor, aos "livros elementares", Condorcet afirma que não seria possível proporcionar uma instrução pública sem seu auxílio. Condorcet enfatizava que tais livros deveriam possuir uma organização metódica do conhecimento desenvolvido pelos melhores estudiosos e seriam utilizados nos três primeiros níveis de instrução, delegando autonomia aos professores para selecionar os textos científicos a serem usados nos níveis subsequentes, o que denota uma clara distinção entre linguagem didática e científica.

Cabe-nos agora identificar o que seria esse saber elemetar para Condorcet. Autores como Kintzler (1994) e Coutel (1996) identificam-no, por um lado, como um ideal de saber mínimo que seria capaz de satisfazer o conjunto de exigências e, por outro, a extensão real dos conhecimentos (alcançados pela humanidade) em um dado momento histórico. Portanto, o conceito de saber elementar, para esses autores, "estabelece uma dupla continuidade entre a razão individual e a razão comum, de uma parte e, entre os sábios e os cidadãos, de outra” (Coutel, 1996, p. 51).

Ressaltamos também que o saber elementar não é um conhecimento voltado para o savoir-faire, sem que se saibam seus fundamentos, de modo que só se aprendem as regras e as etapas de aplicação (Kintzler, 1994, p. 213), o que o caracteriza, a nosso ver, como um ensino não técnico.

Para Silva (2010, p. 11), "o saber elementar não se define unicamente pela sua fidelidade aos cânones epistêmicos. Ele tem a verdade como parâmetro, na medida em que esta é capaz de promover a emancipação política". Trata-se, como bem pontua o autor, de uma proposição eminentemente liberal, em que Condorcet identifica que a emancipação política só poderá ser alcançada à medida que o saber elementar torna-se o marco inicial do processo de instrução, que, uma vez obtido, habilitaria o indivíduo a "aprender por si mesmo", possibilitando o domínio da arte de aprender a aprender, isto é, o desenvolvimento do senso de pesquisa e investigação.

Para além dos "livros elementares", dos textos científicos e do próprio preparo do professor, Condorcet previa no Rapport palestras públicas aos domingos, museu de artes e ofícios, a criação de pequenas bibliotecas em cada escola e o ensino de história natural, para desenvolver o gosto pela observação e análise entre os alunos.

Terrot (1997), ao analisar as proposições de Condorcet, considera-o como o precursor do que chamamos hoje de formação continuada, haja vista que previa quatro fins para esse tipo de formação, isto é, o da justiça social, o da compensação, ou melhor, promover o acesso aos novos conhecimentos, o de eliminar a fragmentação do trabalho e, por último, o da formação para a cidadania.

Nesse contexto, não poderíamos deixar de enfatizar as proposições de Condorcet acerca do processo de formação de professores. É interessante perceber que o filósofo pensou tanto a formação inicial do professor como também seu 
aperfeiçoamento, considerando que tal formação poderia perpassar por todos os níveis de instrução, de forma que poderia ser habilitado, de acordo com o nível alcançado, para o exercício da função nos cinco níveis de ensino normatizados pelo Rapport.

$\mathrm{O}$ autor ainda ratifica que a instrução pública possui uma finalidade específica, isto é, a de formar cidadãos, para que estes não possam um dia dizer que a lei não lhes garantiu uma inteira igualdade de direitos, mas que, no entanto, lhes recusa os meios de conhecê-los, o que se configuraria como uma ausência de autonomia. Nesse sentido, o homem que esteja à margem da instrução pública não poderá pronunciar que depende ou se submete apenas à lei, pois sua não instrução o torna dependente de tudo que o envolve, ou seja, os costumes, os hábitos, os preconceitos e a própria tutela de alguém. A esse respeito, Condorcet enfatiza a necessidade de uma instrução de base e outra "permanente", para que a autonomia não deixe de ser continuamente conquistada (Cf. Silva, 2010).

A instrução deveria ser colocada em prática de forma que possibilitasse a formação do cidadão, o que promoveria o conhecimento dos direitos de cada indivíduo, capacitando-o a participar dos debates em torno da revisão e proposição das leis, como um processo regular, o que Kintzler (1994) e Coutel (1996) identificaram como o "cuidado epistemológico com o verdadeiro", como mecanismo de identificar os argumentos persuasivos de controle e submissão.

Ao examinar atentamente os fatos recentes (final do século XVIII) e do passado mais longínquo, Condorcet depreende que nem o progresso das ciências e artes nem o estabelecimento da democracia política impediriam o surgimento de novas formas de domínio e desigualdade se os povos não fossem esclarecidos em torno das leis e regras que governam o "cosmos" das coisas e dos homens, aprendendo a aplicá-las, corrigi-las, inová-las de forma inteligente e criativa. Nessa perspectiva, somente uma pedagogia empenhada em "ilustrar" todos os seres humanos, independentemente de seu país, religião, cor da pele ou sexo, poderia assegurar a vitória universal e o exercício efetivo dos direitos políticos e sociais conquistados pelas revoluções e fixados nas leis.

Em síntese, Condorcet expõe, no projeto de normatização da instrução nacional francesa (Rapport), seu ideal de uma instrução pública radicalmente laica, unificada e, em tese, aberta a todos. No entanto, trata-se de um marco clássico na história do pensamento pedagógico moderno, em que ratifica sua premissa de que todos os homens são seres dotados de sensibilidade e aptidão para formar raciocínios complexos e ideias morais, cabendo ao Estado, nesse contexto, promover a instrução de seus cidadãos.

É salutar ressaltarmos, ainda, que o progresso científico, o incentivo à produção de invenções de interesse social e a formação, capacitação e preparo do cidadão francês para desenvolver suas atividades sociais a que viessem a ser convocados a desempenhar foram também eixos norteadores do Rapport.

Outro claro interesse do Rapport era o de qualificar a mão de obra francesa para o mercado de trabalho, e como o termo progresso, como bem pontuou Le Goff (2003), esteve ligado a uma ideia de desenvolvimento científico e tecnológico, isso nos faz pressupor que os franceses, a exemplo dos ingleses, estavam preparando-se 
para intensificar a industrialização no país, levando-nos a concatenar essas primeiras considerações ao que afirma o historiador Hobsbawm (1996, p. 7).

Se a economia do mundo do século XIX foi construída principalmente sob a influência da revolução industrial britânica, sua política e ideologia foram constituídas fundamentalmente pela Revolução Francesa.

Ou seja, as teorizações relacionadas à instrução pública também estiveram presentes nessa influência ideológica que a Revolução Francesa repassa às futuras gerações ao longo do século XIX. Desse modo, as teorizações relativas a uma instrução universalizada, como dever do Estado, baseada na moral, na razão e no cientificismo, vieram a ser o grande legado dos ideais franceses, que, reconhecidamente, figuraram como a base do sistema educacional moderno. E, com esse viés, reconhecemos as teorizações de Condorcet como o fundamento que influenciaria as proposições subsequentes, ainda no período revolucionário francês, que se propagaria, posteriormente, por diversas regiões do planeta, entre elas o Império do Brasil.

\section{A ESCOLA UNIVERSALIZADA E A FORMAÇÃO DO HOMEM CIDADÃO}

Os pensadores iluministas de outrora, como Helvétius, Diderot, Rousseau, D'Alembert, Voltaire, Montesquieu, entre outros, e os enciclopedistas, a exemplo de Condorcet, estiveram estritamente ligados ao processo de constituição paradigmática do que representaria, naquele momento, final do século XVIII, a constituição da escola universalizada e a formação do homem cidadão.

Trata-se de teóricos que se dedicaram a estudos amplamente enriquecidos das principais considerações sobre homens, nações, pátria, povo, costumes, economia, política, humanidade etc., que nortearam o pensamento político e científico no século XVIII, promovendo diversas discussões e ações que influenciariam, ou mesmo formariam, a mentalidade daquele denominado por Boto (1996) de "homem novo".

A escola, nesse sentido, passa a ocupar um papel de destaque para a formação desse homem cidadão. A ela é atribuída a tarefa pedagógica de promover os princípios de liberdade e igualdade, tendo como máxima a razão, amplamente difundida pelos teóricos do iluminismo.

Para Cassirer (1992, p. 230):

O século XVIII está impregnado de fé na unidade e imutabilidade da razão. A razão é uma e idêntica para todo o indivíduo-pensante, para toda a nação, toda época, toda cultura [...] das máximas e convicções morais, das ideias e dos julgamentos teóricos, destaca-se um conteúdo firme e imutável, consistente, e sua unidade e sua consistência são justamente a expressão da essência própria da razão.

Não nos deteremos aqui em elaborar uma narrativa detalhada dos pressupostos teóricos dos pensadores iluministas elencados anteriormente, mas sim em perceber suas influências para a formação de uma cultura escolar que servirá como base para entendermos nossas discussões posteriores. 
Boto (2003) ressalta que o propósito iluminista de superar e fazer frente à rigidez da pedagogia do colégio, entendida como o ensino vinculado à Igreja, em suas marcadas estruturas, é acompanhado por um desejo de transformação da vida social e política, em suas hierarquias e fronteiras. Diante disso, a autora enfatiza ainda que:

O século XIX assiste, finalmente, com a consciência de quem pretende perpetuar o feito, à institucionalização da pedagogia como uma ciência específica da educação, e, portanto, com patamares de autoridade; [...]. A pedagogia propunha-se, desde então, como um campo do saber cuja meta seria o rompimento dos pilares da tradição, para firmar conceitos teóricos e procedimentos metodológicos que se apresentassem universalmente válidos e cientificamente comprovados para preparar o caminho das gerações vindouras. (idem, p. 379-380)

A antítese antigo/moderno, nesse contexto, torna-se importante para entendermos os pressupostos teóricos que inauguram essa pedagogia moderna no século XIX, como bem pontuou a autora no texto citado. Desse modo, percebemos uma total dualidade entre os dois conceitos, uma vez que o fato de "descompor hábitos e crenças" anteriores é também uma negação à tradição, ao antigo.

Segundo o historiador francês Le Goff (2003), na Europa do final do século XVII e início do XVIII, "antigo" tornou-se sinônimo de "superado", e "moderno", de "progressista", muito em razão dos avanços científicos e tecnológicos da época, que acabaram por moldar o conceito de progresso.

Retomando a discussão acerca da função atribuída à escola "moderna”, percebemos que o modelo educacional a ser adotado por ela é aquele que irá renegar as convenções e as tradições, isto é, a escola moderna precisará, necessariamente, tornar-se universal e ter como princípio básico a formação do homem cidadão.

Eisenstein (1998) ressalta que a formação do "homem novo" já começa a moldar-se a partir de uma cultura impressa, isto é, a partir da invenção da imprensa no século XV, completando essa constituição, a nosso ver, com os processos das revoluções burguesas do século XVIII, com destaque para a Revolução Industrial Inglesa e para a Revolução Francesa de 1789. Assim, para a referida autora, essa cultura impressa teria constituído

[...] um "homem novo"; [...] perito igualmente em lidar com máquinas e comercializar produtos, ao mesmo tempo em que editava textos, fundava associações culturais, promovia artistas e autores ou fazia progredir novas formas de coletar dados e diversos ramos de disciplinas eruditas [...]. (idem, p. 158)

Boto (2003) ressalta que a partir desse novo éthos social o homem passaria a confiar mais em suas capacidades de interpretar e decifrar o universo. Chartier (1987) alude que essa "cultura escrita" foi constituindo-se por meio da circulação de diversos almanaques, cartazes, manuais, literatura de cordel, catecismos, entre outros, que acabaram por influenciar as configurações de uma mentalidade circunscrita na autonomia do homem. 
A enciclopédia, por essa forma, torna-se outro importante elemento para a formação dessa "cultura escrita". Por meio da enciclopédia foram publicizados diversos textos que teciam considerações relacionadas a temas referentes ao homem, à sociedade, ao Estado, entre outros. Foi também uma forma de reunir estudos e debates de teóricos que se dedicavam a analisar diferentes temas sociais, entre eles a educação.

A soberania do Estado, a partir das teses de Hobbes e Rousseau, também é uma das questões para a constituição da cultura escolar, que passará a ser amplamente difundida no decorrer do século XIX (cf. Boto, 1996).

Para entendermos melhor essa questão acerca da soberania do Estado e da constituição da cultura escolar, podemos retomar, como base, as proposições de Condorcet, quando evidencia a diferenciação entre educação e instrução, haja vista que Hobbes e Rousseau foram pensadores iluministas que fizeram parte da constituição teórica de Condorcet para a elaboração de suas proposições de institucionalização da instrução nacional francesa, bem como para a constituição de um pensamento pedagógico que marcou de forma indelével as aspirações pela constituição do homem cidadão.

Ocorrerá, a partir de meados do século XVIII, uma intensificação do pensamento pedagógico e da preocupação com a atitude educativa. Para alguns filósofos e pensadores do movimento francês, o homem seria integralmente tributário do processo educativo a que se submetera. A educação adquire, sob tal enfoque, perspectiva totalizadora e profética, na medida em que através dela, poderiam ocorrer as necessárias reformas sociais perante o signo do homem pedagogicamente reformado. [...] Das relações mestre e discípulo às determinações políticas do ato pedagógico, tudo isso seria considerado decorrente de um fator preliminar, concernente à identificação dos mecanismos propulsores do aprendizado humano. (idem, p. 21-22)

A escola, nesse contexto, entendida como elemento indispensável para a formação do homem, passa a ser o meio pelo qual se difundiriam os conhecimentos necessários para a constituição do homem cidadão. É ela também, segundo a autora, quem seria "[...] capaz de imprimir na alma dos novos cidadãos o registro da sociabilidade inédita que recriaria os costumes, os hábitos, os valores e a própria tradição" (idem, p. 99).

A partir dessa conjuntura, a escola passa a ser o meio pelo qual o princípio de instrução, defendido por Condorcet, seria propagado na França após 1789. Assim, a escola reconfigura-se na esfera pública, com a estrita missão de moldar uma nova nacionalidade, marcada por acepções de cidadania e soberania.

Condorcet, por meio das proposições tecidas no Rapport, atribuía à instituição escolar a tarefa de formar o homem cidadão, que pudesse constituir uma sociedade verdadeiramente democrática, na qual todos poderiam ter participação política e ser conscientes de seus direitos e deveres.

A escolarização teria a missão de formar o cidadão consciente de sua cidadania e dos princípios que configurariam os preceitos sociais da nova sociedade francesa que se queria moldar. E, para que todos tivessem acesso a essa escolarização, esta teria 
de ser subsidiada pelo poder público, de modo que mantivesse o caráter universal da escola que se pretendia firmar.

Concebida como um dever social, a instrução pública, por meio da escolarização, instituía-se como direito, que se pretendia figurar e que irradiaria os postulados revolucionários franceses, de maneira que, concomitantemente, abarcaria as esferas sociais marginalizadas pelo Antigo Regime.

Condorcet enfatizava que a instrução pública, por meio da escola, seria o elemento essencial para a formação do homem cidadão, que, uma vez instruído, deveria buscar a perfectibilidade da sociedade, isto é, para a constituição de cidadãos ideais, usando para tal fim a racionalidade, a moralidade, a intelectualidade, que seriam alcançados por uma educação sistematizada.

Destarte, ao abranger todas as classes sociais e todos os gêneros em suas proposições presentes no Rapport de 1792, a instrução nacional como dever do Estado proporcionaria as condições necessárias para educar e formar um homem cidadão, capaz de alcançar o ideal proposto pelos princípios revolucionários de igualdade, liberdade e fraternidade em sua plenitude.

As prerrogativas da escola como irradiadora das luzes e de uma instrução de caráter universal também perfizeram o ideal formativo do homem cidadão, que estaria imune aos postulados tradicionais que marcaram a sociedade francesa durante o Antigo Regime.

\section{O PROFESSOR ILUSTRADO E APLICADO}

Entre as mais variadas proposições e teorizações acerca da institucionalização da instrução pública tecidas por Condorcet, percebemos um claro esforço do teórico em promover um rico processo de formação dos professores que passariam a atuar no sistema de instrução nacional francês.

Os institutos e liceus, isto é, dois níveis do sistema educacional francês, estariam diretamente relacionados ao processo de formação de professores, o que denota a ênfase atribuída pelo teórico à necessidade de se formar professores que estivessem comprometidos com o ideal de constituição do homem cidadão, isto é, professores que estivessem devidamente "treinados" para atuar em uma escola caracterizada pela instrução de feição universal, pautada na razão, na moral, na cientificidade e nos princípios da liberdade e igualdade.

O professor, então, deveria estar devidamente afinado aos ideais iluministas de cientificidade e da razão para ser o propagador dos conhecimentos "elementares" para a formação do cidadão francês que se queria moldar, ou seja, que estivesse totalmente alheio aos velhos paradigmas do Antigo Regime, além de ser encarado como facilitador para o aprimoramento da mente do cidadão, que, por meio dos conhecimentos elementares e da própria disseminação do progresso científico das mais variadas áreas do conhecimento, tornar-se-ia indubitavelmente um indivíduo consciente de seus direitos, deveres e de sua capacidade de proposição e interpretação.

No Rapport de Condorcet, a razão e a moral deveriam ser inculcadas no homem cidadão por meio da instrução pública de caráter universal, sendo ainda o principal direcionamento para a atuação do professor. Assim sendo, o professor teria 
de ser formado à luz dos conhecimentos científicos e da própria razão, uma vez que aquele seria a base para a construção de uma nova mentalidade que se queria moldar entre os cidadãos da nova França, isto é, da França totalmente alheia aos hábitos e costumes que a caracterizavam anteriormente à revolução de 1789 .

Nesse contexto, o processo de formação de professores, teorizado na França, após a revolução de 1789 , possuía um caráter eminentemente científico, que acaba por ser a marca da escola universalizada e da própria noção de conhecimento empregada por seus teóricos.

Assim, a formação do professor não se poderia deter ao processo de capacitação para o ensino das luzes ao indivíduo particular, mas à sociedade como um todo, de forma que possibilitasse, segundo as proposições de Condorcet, a compreensão de que o conhecimento precisa ser enriquecido por novas verdades, como forma de aperfeiçoar a mente humana para o desenvolvimento de novas maneiras de acelerar e promover o progresso científico e social.

Em diversos momentos de suas proposições, Condorcet enfatiza que, para além das aulas ministradas nos ambientes escolares, os professores deveriam estar preparados para disseminar as luzes para a sociedade, tendo em conta que seriam convocados a proferir palestras públicas que versassem sobre importantes temas para a constituição de um senso de justiça e de sociedade entre os cidadãos franceses.

Os institutos, segundo o Rapport, teriam a premissa de formar professores para as escolas primárias e secundárias, com um currículo que englobaria elementos de todas as áreas do conhecimento humano, o que estaria estritamente de acordo com o objetivo desse nível de instrução, ou seja, o de habilitar seus alunos para cumprir as funções públicas a que seriam chamados - no caso, a função de professor.

Os professores, dessa maneira, receberiam uma formação permeada por um ideal filosófico livre de qualquer interferência política, civil ou de qualquer outra instituição, no sentido dos interesses particulares, de qualquer velho hábito, ou seja, livre de qualquer pensamento considerado retrógrado.

As escolas secundárias, no entanto, representavam a primeira instância de formação docente, tendo em vista que era nessa instituição, de nível secundário, que os professores da escola primária receberiam sua primeira formação.

Já os liceus, para além de uma instituição destinada a formar cientistas, possuíam também a missão de promover o aperfeiçoamento de professores. Condorcet afirma que é por meio dessas instituições que os conhecimentos, o que ele mesmo denominou de "verdades", seriam aprimorados e transmitidos para as gerações futuras.

Nessas instituições de formação e aprimoramento de professores, o ensino deveria estar diretamente relacionado com o que havia de mais recente na Europa, como os progressos alcançados pela ciência. Teriam ainda de possuir os mais respeitáveis professores do continente, uma vez que não admitiriam qualquer tipo de inferioridade em relação às demais instituições, do mesmo nível de instrução, de qualquer outro país europeu.

Condorcet concebia que os liceus precisariam acompanhar anualmente os progressos e avanços das ciências, de forma que pudessem garantir à nação francesa 
instituições de alto grau de cientificidade, bem como a formação e o aperfeiçoamento de professores estritamente afinados aos ideais de constituição do novo homem, isto é, do cidadão francês que se pretendia formar.

\section{CONSIDERAÇÕES FINAIS}

Após essa breve análise histórica sobre os ideais modernos de instrução, que discutimos por meio do Rapport de Condorcet e Lepelletier, do Projeto de Romme e das proposições de Lakanal, depreendemos uma série de ideias e modelos de instrução que passaram a influenciar as discussões acerca da constituição de sistemas de ensino no mundo que denominamos de moderno. Ratificamos, nesse sentido, o que estudos anteriores já haviam constatado, ou seja, que as discussões tecidas após a Revolução Francesa de 1789 - diríamos que principalmente as proposições de Condorcet - são a base para o entendimento da discussão e dos sistemas de instrução colocados em prática em diversas regiões do planeta.

Com esse processo de influência de ideias, nosso intento para este artigo foi o de compreender as especificidades de um modelo, o francês, que indubitavelmente esteve presente nos meandros históricos do processo de criação e consolidação do sistema de instrução pública no Brasil, o que já foi alvo de observância de estudiosos como Boto (1996), França (1997), Saviani (2009), Tanuri (2000), Villela (1990), Xavier (1992), entre outros, o que ratificamos como fundamental para entendermos a história da educação de nosso país.

Desse modo, constatamos a aproximação dos ideais franceses às proposições das assembleias Constituinte e Geral brasileiras, a partir de 1823, sobre as questões relacionadas à necessidade de se introduzir um sistema de instrução pública no Brasil. Porém, depreendemos que houve projetos antagônicos para a colocação em prática desse sistema, e o projeto que se sobressaiu foi o das elites, definindo um sistema de instrução insipiente para o povo e um projeto diferenciado de educação superior para a elite nacional (cf. Xavier, 1992).

Depreendemos ainda que a própria aspiração por reformas no sistema de instrução pública e pela necessidade de se formar os professores partiu de uma ambiência política, econômica e social que propiciou esse debate. Nesse sentido, os ideais de ordenamento, progresso e civilização foram enfatizados nos discursos que justificavam a necessidade de se instituir o processo de preparo de professores "ilustrados e aplicados", que estivessem afinados com a nova forma de se viver e de se pensar no mundo moderno.

Destarte, o debate em torno de uma instrução pública (universalizada) pautada nos ideais modernos de progresso, ordenamento e civilização passou a ser constante ao longo do século XIX no Brasil, preconizando a instauração de um sistema público de ensino para formar cidadãos à luz da ciência e da razão, como postulado por Condorcet em seu Rapport de 1792, o que ratifica a necessidade de revisitarmos as teorizações de Condorcet para entendermos os desdobramentos teóricos e conceituais na configuração do sistema público de instrução disseminado por várias províncias do Império ao longo do século XIX, o que se tornou fundamento para entendermos a historicidade da educação brasileira. 


\section{REFERÊNCIAS}

Arago, F. Oeuvres de Condorcet. Biographie. v. I. Paris: F. Didot Frères, 1847-1849. Réimpression F. Frommann Verlag, Stuttgart, 1968.

Arroyo, M. La fuerza de la religión y la secularización en Europa. Iglesia Viva, Valencia (España): Asociación Iglesia Viva, n. 224, p. 99-106, 2005. Disponível em: <www. iglesiaviva.org >. Acesso em: 20 fev. 2007.

Baker, K. M. The Old Regime and the French Revolution. Chicago: The University of Chicago; Press Books, 1987.

Barbier, M. Pour une définition de la laïcité française. Le Débat, Paris: Gallimard, n. 134, mars/avril 2005.

Baubérot, J. Les laïcités dans le monde. 2. ed. Paris: PUF, 2009.

Bото, C. A escola do homem novo: entre o Iluminismo e a Revolução Francesa. São Paulo: Editora UNESP, 1996.

A civilização escolar como projeto político e pedagógico da modernidade: cultura em classes, por escrito. Cadernos CEDES, Campinas: CEDES, v. 23, n. 61, p. 378-397, dez. 2003. Disponível em: <http://www.cedes.unicamp.br>. Acesso em: 20 jan. 2012.

Cassirer, E. A filosofia do Iluminismo. Campinas: Editora da UNICAMP, 1992.

Chartier, R. Lectures et lecteurs dans la France d'Ancien Régime. Paris: Seuil, 1987.

Condorcet, M. J. A. N. C. Rapport et projet de décret relatifs à l'organisation générale de l'instruction publique. Présentation à l'Assemblée Législative: 20 et 21 avril 1792. Disponível em: <http://www.assemblee-nationale.fr/histoire/7ed.asp>. Acesso em: 15 jun. 2012.

Coutel, C. À l'école de Condorcet. Contre lorléanisme des esprits. Paris: Ellipses; Éditions Marketing S. A., 1996.

Dupas, G. O mito do progresso. São Paulo: Editora UNESP, 2006.

Eisenstein, E. L. A revolução da cultura impressa: os primórdios da Europa moderna. São Paulo: Ática, 1998.

Elias, N. O processo civilizador: formação do Estado e civilização. Rio de Janeiro: Jorge Zahar, 1993.v. 2.

FrançA, M. P. S. S. A. Raízes históricas do ensino secundário público na provincia do Grão-Pará: o Liceu Paraense. 1997. Dissertação (Mestrado) - Faculdade de Educação, Universidade Estadual de Campinas, Campinas, 1997.

Granger, G.-G. La mathématique sociale du marquis de Condorcet. Paris: PUF, 1956. Paris: Odile Jacob, 1989.

Hobsbawm, E. J. A Revolução Francesa. Tradução de Maria Tereza Lopes Teixeira e Marcos Penchel. Rio de Janeiro: Paz \& Terra, 1996.

Journal D'Instruction Soctale. Sur l'instruction publique, premier mémoire, 1791. Disponível em: <http://www.assemblee-nationale.fr/histoire/7ed.asp>. Acesso em: 26 out. 2012. 
Kintzler, K. C. Condorcet, l'instruction publique et la naissance du citoyen. Paris: Folio Essais, Minerve, 1994.

Le Goff, J. História e memória. Tradução de Bernardo Leitão, Irene Ferreira, Suzana Ferreira Borges. 5. ed. Campinas: Editora UNICAMP, 2003.

Luzuriaga, L. História da educação pública. São Paulo: Nacional, 1959.

Saviani, D. Formação de professores: aspectos históricos e teóricos do problema no contexto brasileiro. Revista Brasileira de Educaşão, Rio de Janeiro: ANPEd; Campinas: Autores Associados, v. 14, n. 40, p. 143-155, jan./abr. 2009. Disponível em: <http:// www.scielo.br/pdf/rbedu/v14n40/v14n40a12.pdf>. Acesso em: 6 jun. 2011.

Sılva, S. R. Direitos humanos e instrução pública segundo Condorcet. Educação em Revista, Marília: UNESP, v. 11, n. 12, p. 1-18, jan./jun. 2010. Disponível em: <http:// www2.marilia.unesp.br/revistas/index.php/educacaoemrevista/article/view/661/544〉. Acesso em: 22 nov. 2011.

TANuri, L. M. História da formação de professores. Revista Brasileira de Educação, Rio de Janeiro: ANPEd; Campinas: Autores Associados, n. 14, maio/ago. 2000. Disponível em: <http:/www.scielo.br/pdf/rbedu/n14/n14a05>. Acesso em: 26 out. 2012.

Terrot, N. Histoire de l'éducation des adultes en France, la part de l'éducation des adultes dans la formation des travailleurs: 1789-1971. Paris: Éditions L'Harmattan, nouvelle édition mise à jour, 1997.

Villela, H. O. S. A primeira escola normal do Brasil: uma contribuição à história da formação de professores. 1990. Dissertação (Mestrado) - Faculdade de Educação, Universidade Federal Fluminense, Niterói, 1990.

Xavier, M. E. S. P. Poder politico e educação de elite. 3. ed. São Paulo: Cortez; Autores Associados, 1992.

\section{SOBRE OS AUTORES}

Rogério Guimarães Malheiros é mestre em educação pela Universidade Federal do Pará (UFPA). Professor da rede municipal de ensino de Parauapebas. E-mail: rogeriomalheiros@yahoo.com.br

Genylton Odilon Rêgo da Rocha é doutor em geografia pela Universidade de São Paulo (USP). Professor da Universidade Federal do Pará (UFPA). E-mail: genylton@gmail.com 